\title{
Analysis of the Information Flow within the Information System of Car Parks
}

\author{
Zoran Nesic $^{1}$, Leon Ljubic ${ }^{2}$, Miroslav Radojicic ${ }^{1}$ and Jasmina \\ Vesic Vasovic ${ }^{1}$ \\ ${ }^{1}$ University of Kragujevac, Faculty of Technical Sciences \\ Svetog Save 65, 32000 Cacak, Serbia \\ ${ }^{2}$ JKP "Parking Service Kragujevac “ \\ Vojislava Kalanovica b.b., 34000 Kragujevac, Serbia \\ E-mail: zoran.nesic@ftn.kg.ac.rs, leon.ljubic@parkingservis.rs, \\ miroslav.radojicic@ftn.kg.ac.rs, jasmina.vesic@ftn.kg.ac.rs
}

\begin{abstract}
In this paper, the major elements of the information flow in car parks information system has been presented. A detailed analysis of information flow in one of the key elements for a parking service company, thus, providing the basis for developing the information system in this area. The analysis of decomposition diagrams and charts, in the context of the information flow, has also been presented here, as well as, the formation of a logical and relational database model. The focus is on the performance of a detailed analysis of the information flow, with the aim of improving the overall functioning of a parking service company. The development of the information system of car parks is the most important step in both the development of the overall information system of this company and its improvement. The results presented in this paper might be a starting point in the development of information systems for parking service companies, in general. The obtained results help in the formation of a clear and consistent information system in this area.
\end{abstract}

\section{Introduction}

The information system of a parking service company is a tool by which service information, as well as, information about the decision-making processes, at all levels, is provided to citizens/users. Accordingly, it should be an integral part of the information system of the city. From that aspect, this information system is actually a tool for decision-making in the areas of service and control; therefore, it is a part of a wider information unit. 
Development of the information system of a parking service company is based on the legal requirements [1] - [3] and the general management methodology [4] [6].

The first and most important advantage of such an information system, is that it provides information to the user, preferably in real time. This generally refers to the information concerning the availability of parking spaces and areas but also about simplified parking payment and other useful services (working/non-working days, zones where parking is allowed, etc).

Another advantage is that the operating processes of a parking service company are integrated into an optimized system, by which management irrationality is eliminated. Processes become tightly linked with no possibility for interruption; therefore, there is no loss of information and no risk of unauthorized access to information. Also, the processes, tasks and activities within individual processes are clearly distinguished in this way; as a consequence, the existing organizational model of processes, tasks and activities remains constant.

The third advantage is optimal management of company's resources, so that it is possible to predict the future state of the company based on the current state. This is very important for determining future goals, strategies and plans and for determining the overall business policy on which the entire management will be based. The term "resources" refers primarily to the area of land that is or will be a part of the parking area. The information system provides information which represents the basis for making good decisions on optimized management of the existing parking areas and on the use of new parking areas. The term "optimized management" refers to the optimal use of parking areas but also the optimal engagement of the personnel and resources involved in the work process. In addition, we should mention the transport infrastructure resources which are very important for the implementation of parking rules. Other resources are people and labour force, capital assets, financial resources, etc.

The fourth advantage is the integration of such an information system into a unique future information system of the city, which will take a decision-making process to the higher level.

The fifth advantage, which unites all other advantages, is provision of simplified decision-making process at all levels of management. It will give the decision maker one or more alternatives which are the result of realistic and precisely defined state of the system, i.e. company.

This paper is based on the fundamental concepts of information systems [7] - [11] and databases [12] - [17] development. 


\section{Car Park Management Function}

This function includes the processes, activities and operations used in managing parking areas in terms of meeting the users' / citizens' needs for parking. Therefore, the emphasis is not on the parking area as a resource, but on a parking area as means for satisfying the needs of users. All parking areas are divided into two main types - open car parks and special car parks.

Open car parks are the unconfined urban public areas where parking is allowed. These parking areas may be in the street, on the sidewalk or around the buildings. Parking spaces are marked with vertical and horizontal signals. Open car parks are divided into zones; there are three zones $-0,1$ and 2. Each zone has special parking rules due to which the users' needs are met in optimal way.

Zone 0 is the zone that covers the city centre; in this zone, parking is limited to 2 continuous hours after which the user must remove the vehicle and may re-park there again after one hour break and stay there for another two hours. For zone 1 and 2 there are no limits regarding parking hours, i.e. the user can park for an indefinite period of time regardless of the time of day. Zones 1 and 2 include the wider city centre and parts between wider city centre and periphery.

By paying for parking via a SMS payment system or by purchasing a paper ticket, the user becomes entitled to a parking space and he/she undertakes the obligation to respect the rules of the particular parking zone.

Control is performed by parking attendants who use a computer device by which they send an enquiry to the central computer and receive information for the specific vehicle regarding payment and parking hours. If the attendant detects that the vehicle owner has exceeded the number of paid parking hours or perhaps has not paid for the parking, he or she must issue a special daily ticket which is a part of the price list and is valid for 24 hours excluding non-working days and holidays.

That means that the user is obliged to pay that special daily ticket in the following period and in return he or she can park in all parking zones in the next 24 hours without any restrictions. Naturally, a parking service company plans to make the citizens use the SMS payment system or scratch tickets more often, with the purpose of reducing the parking congestion in central city zones and directing the vehicles towards city periphery. On the other hand, a special daily ticket is a form of penalty for irresponsible users; it should improve their awareness of the need to respect the parking rules.

Special car parks are all parking areas that are confined and the entrance to the area is paid per hour of parking. There are no limitations for parking at special car parks, but the user must respect the same general traffic rules which apply to open car parks. 
Upon entering the special car park, the user is issued a parking confirmation which includes the date and time of entry, license plate number, car park index, price per hour, name of the employee who has issued the parking confirmation and some other status information.

When leaving the special car park, the user submits the parking confirmation and makes the payment; after that, he/she is issued a receipt similar to the parking confirmation, with the additional information about the number of hours, as a basis for payment, and the total amount to be paid. By this activity the user, i.e. vehicle, is relieved of debt. If for some reason the user fails to pay, it will be forbidden to park that vehicle at any other special car park until the due debt is settled.

In addition to special car parks, there are also truck terminals where the rules are similar to those of special car parks.

\section{Analysis of Information Flow in Car Parks Management Function}

Figure 1 shows a context diagram that displays all the inputs, outputs, controls and mechanisms essential for the best possible functioning of the parking process.

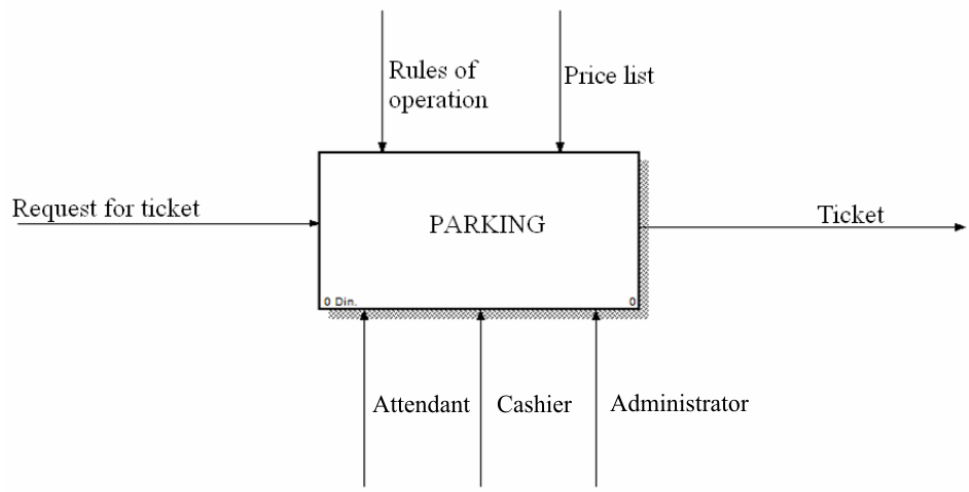

Figure 1

Context diagram for car park management function

A request for the ticket represents the input information. It is not a standardized document, but instead a general entry information by which the user expresses the need to buy a ticket, i.e. to use the parking service. This request usually has the form of an SMS or a ticket bought in the parking service company office or in one of the shops. Also, there is a category of disabled parking tickets that are free of charge, but are issued to the user through a special request. 
Output information is a ticket that can have the form of a paper ticket or an SMS ticket. There are many types of tickets which a parking service company can sell:

- Electronic SMS tickets which can be hourly and daily

- Scratch tickets which can also be hourly and daily

- Monthly season tickets which are valid for a longer period of time

- Residential tickets issued to residents of objects located in parking sectors

- Tickets that are issued to users at special car parks

Internal Rules of Procedures, formed by a parking service company for the purpose of unifying work processes and activities, are applied as a mechanism. A price of the ticket is another mechanism. This mechanism is based on the price list of a parking service company and it is approved by the City Assembly.

As shown below, the elements of control are a parking attendant, a cashier and an administrator.

Figure 2 shows that this function consists of two processes: parking payment and parking payment control. The process of parking payment is the process by which parking conditions are assessed and money for parking is collected. For the process of parking payment, the input is a request for the ticket, and the output is a confirmation of ticket purchase. This confirmation may have the following forms:

- Electronic SMS confirmation that the user receives from the electronic payment system on the device from which SMS request for a ticket was sent. In this way the user is informed that the request was successfully completed and that the required SMS ticket is in the ticket database.

- For a scratch ticket for open car parks it is a scratch ticket itself, which is later cancelled by the attendant who puts it back into the system to be reused.

- For monthly season and disabled parking tickets, it is a plastic card which is issued to the user. After this type of ticket had been issued to the user, it is inserted into the database so that the attendants can check it.

- For residential tickets in open car parks, it is a sticker which represents both the ticket and the receipt. It is placed on the windscreen and it serves as a visual confirmation which facilitates the control.

- Confirmation at special car parks has the form of slip receipt which represents both the ticket and the confirmation of purchase.

The elements of the mechanism are various Rules of Procedures and valid price list, which are explained in the section on the context diagram.

Elements of control are also an attendant, a cashier and an administrator who issues monthly season, disability and residential tickets. 


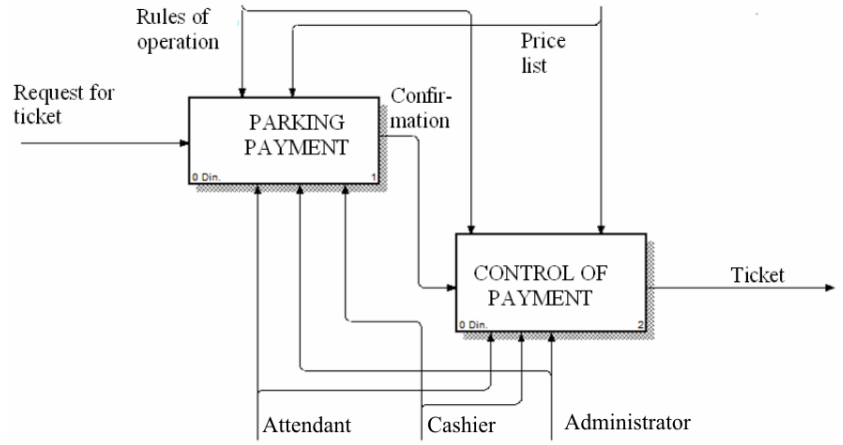

Figure 2

Decomposition diagram for the parking management function

Parking payment control is the process which includes control of payments, i.e. correctness of the payment elements.

The input for this process is the confirmation generated in the process of parking payment, and output is the ticket itself. Same as in parking payment process, control is exercised through a variety of regulations and price lists. Executive mechanisms are an attendant, a cashier and an administrator.

In Figure 3 all the activities used in parking payment process are presented. There are six activities that take place at the same time. They all have their specific characteristics reflected in the various procedural steps of the parking payment process. However, they all have the same input, i.e. request for a ticket that is generated by the user and can have different forms.

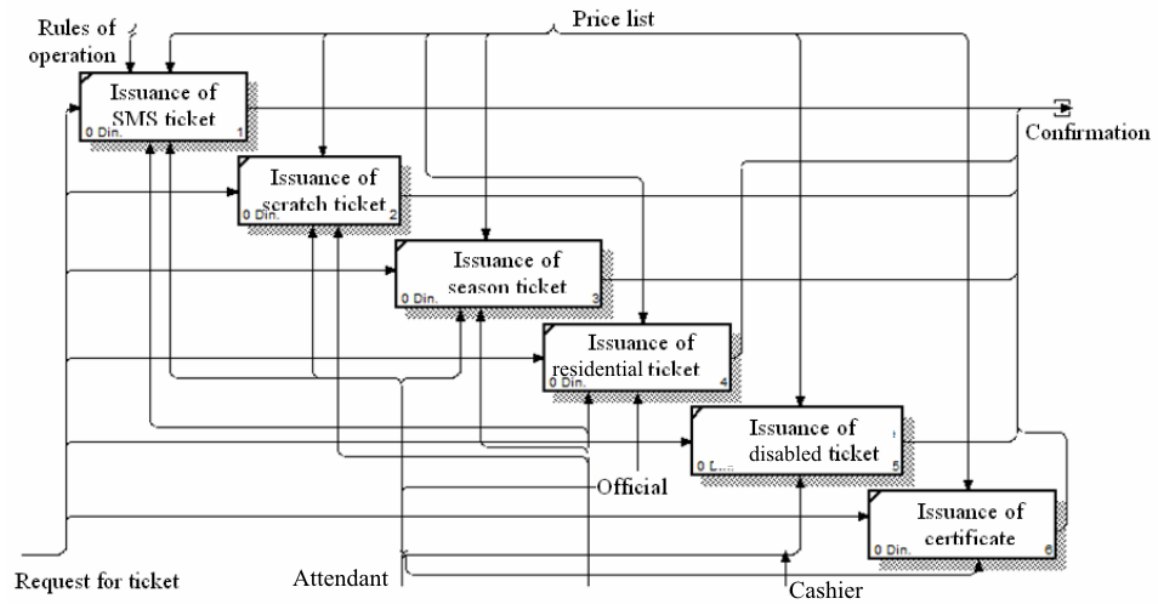

Figure 3

Diagram of the first level in the parking payment process 
The output for all the activities is a confirmation issued to the user. Sometimes the ticket is used as a confirmation and sometimes the confirmation is used as the ticket.

The controls are performed according to a variety of regulations that are generally called the Rules of Procedures, as well as according to the valid price list.

Mechanisms are an attendant, a cashier and an administrator. The attendant is a mechanism that performs the control of SMS and scratch tickets payment. The administrator is a mechanism engaged in charging for parking via monthly season tickets and residential tickets and in issuance of the disabled parking tickets. The cashier at special car parks is a mechanism that issues confirmations which are also the tickets.

Figure 4 shows that confirmations generated in parking payment process are the input to the activity of parking payment control. This activity involves the paid tickets control, but not the payment itself. Elements of control are also Rules of Procedures and the valid price list. The mechanisms are attendants, cashiers and administrators.

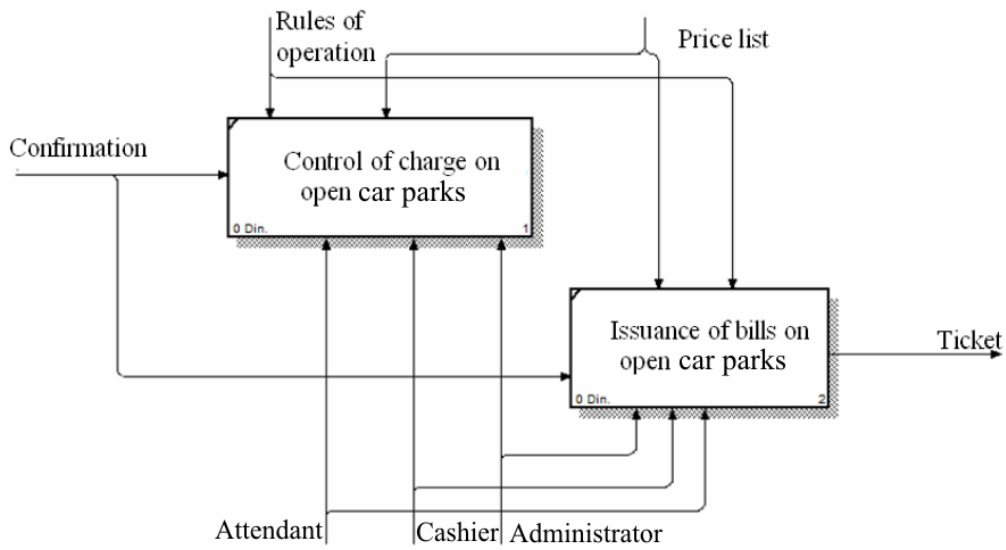

Figure 4

Diagram of the first level for parking payment control process

Issuance of receipts at special car parks is an activity by which procedures for issuing receipts are grouped, since the receipt issuing at special car parks is specific - the issued ticket is at the same time the confirmation.

At special car parks, the output of this activity is the ticket itself. Elements of control are Rules of Procedures and the valid price list. Mechanisms are cashiers and administrators. 


\section{Results and Discussion}

A preliminary analysis of information flow was the most important step in the creation of the information system. That analysis has provided the basis for the creation of a relational database model, as well as for the following major phases of information system development. The creation of the relational database model is the basis for further analysis of information from different aspects [18] and for the use of various business intelligence methodologies [19] - [21]. There are five tables in this model. Some tables are code-books, such as Worker, Zone, Street.

All entities from the group of independent entities are candidates for code-book tables. A dependent entity - the ticket - is a candidate for generated tickets table. Derived entity Zone / Street is an entity via which available data on Street - Zone relation are generated, since these relations are changeable and depend on the activities of a parking service company. The tables that appear in the relational model for this function are presented in Figure 5: Worker, Ticket, Zone, Price list, Street and Zone / Street. Independent entities are Employee, Zone, Price list, Street. A dependent entity is a Ticket. Derived entity is Zone / Street.

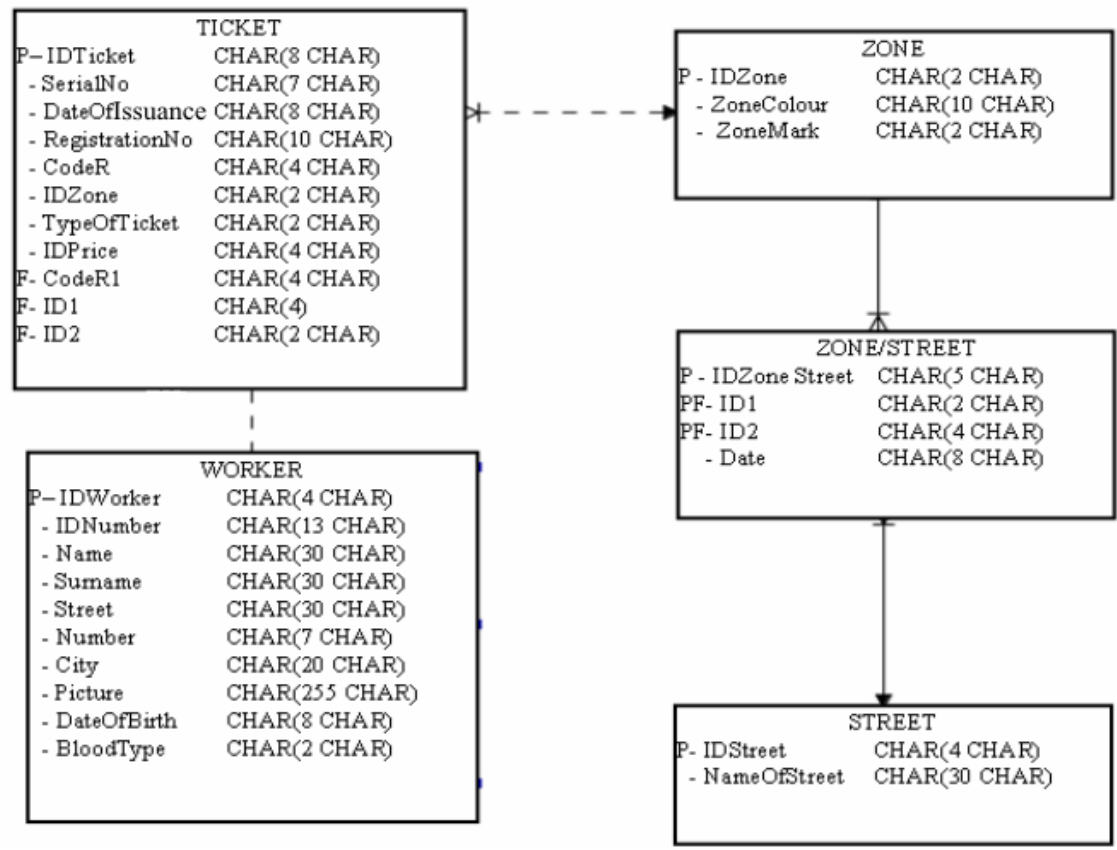

Figure 5

The relational data model for car park management function

Creation of the relational database model has enabled obtaining of numerous database analyses. Figure 6 presents results from the main table for this function. 
The most important information on issued tickets for open and special car parks is as follows:

- ID Ticket, identifier of a record in a set of all records. It is necessary for internal processing in the future application.

- Serial number, mark of the ticket issued to the user. This mark serves for identifying the document TICKET and is typically located on the physical document TICKET. In case of SMS, disabled parking or season tickets, it is a unique number that is generated by the system.

- Issuance date, the date of issuance of the document TICKET.

- Registration mark, license plate number of the vehicle for which the ticket is issued.

- Code of the employee obtained from the outer table - employees' code-book.

- Zone code from the outer table - zone code-book

- Type of ticket, code of the type of ticket issued by the employee. 01 - special day ticket, 02 - residential ticket etc.

- Identification of prices from the price list, i.e. pricelist code-book

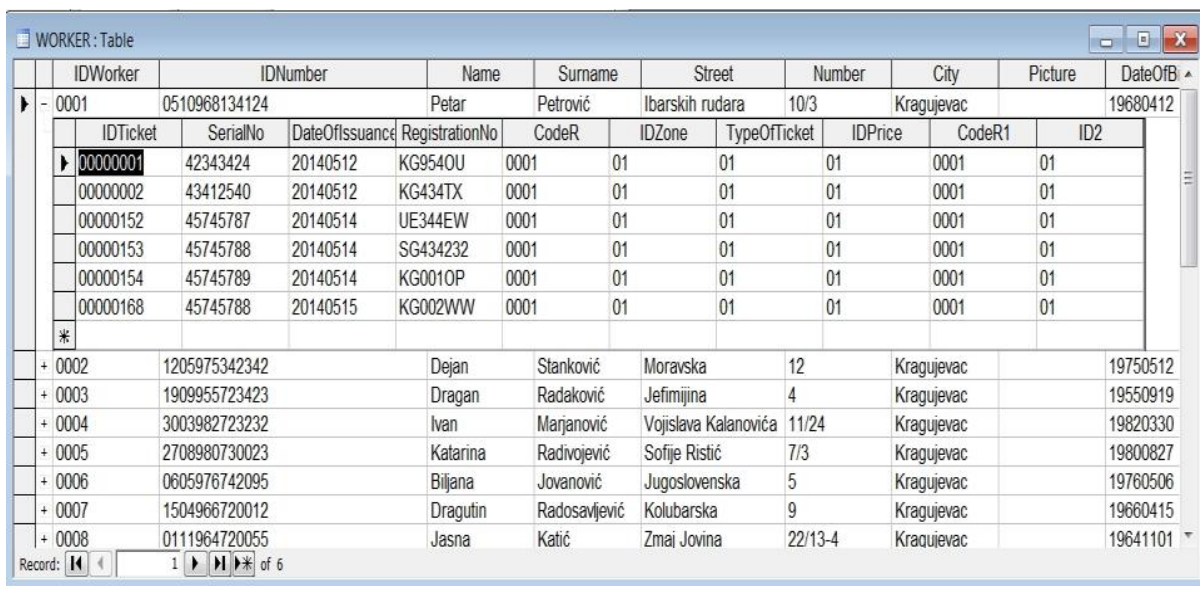

Figure 6

Results of the database analysis

Based on the relational database model, Figure 6 shows the corresponding data about employees who have issued the tickets:

- IDWorker - field for the identification of records on a particular employee. It is used only for internal purposes of the future application. 
- Personal identification number, a field which contains data on personal identification number (PIN). This is necessary because PIN is gaining importance increasingly as a unique property of a person, i.e. an employee. Most operations in the future application are based on a PIN number (or rather the mark).

- Name - Employee's name

- Last Name - Employee's last name

- $\quad$ Street - Street in which an employee resides

- Number - mark of the residential unit in the street in which an employee resides.

- City - identification of the employee's city of residence

- Photo - a field which contains the photo of an employee or a hyperlink to a location on the disk where the employee's photo is located.

- Date of birth - information on an employee's date of birth in the format YYYY-MM-DD, because it facilitates data processing; therefore, there is no dependence on the local settings of date and time.

Further use of the relational database model allows obtainment of more information about the zones. It plays the role of a code-book in the data model. The most important information is identification of records on a particular zone. It is used solely for internal purposes of the model, as descriptive information of a certain zone. It is used for easier zone identification by the user and as official zone mark.

Based on this, it can be concluded that there is an upward trend regarding income which is the result of the introduction of Information subsystem for car parks management. Based on the analysis of data from Business plan of JKP Parking Servis Kragujevac for 2008-2013 [1], there has been an increase of over $75 \%$ since 2008, when the IS was introduced, Table 1 and Figure 7.

Table 1

Income from open and special car parks

\begin{tabular}{|l|l|l|l|l|l|l|l|}
\hline Year & 2007 & 2008 & 2009 & 2010 & 2011 & 2012 & 2013 \\
\hline $\begin{array}{l}\text { Income from } \\
\text { open car parks }\end{array}$ & 24.479 & 42.990 & 55.321 & 52.051 & 56.696 & 65.533 & 69.124 \\
\hline $\begin{array}{l}\text { Income from } \\
\text { special car parks }\end{array}$ & 19.296 & 21.409 & 27.249 & 35.470 & 47.521 & 54.067 & 57.704 \\
\hline
\end{tabular}




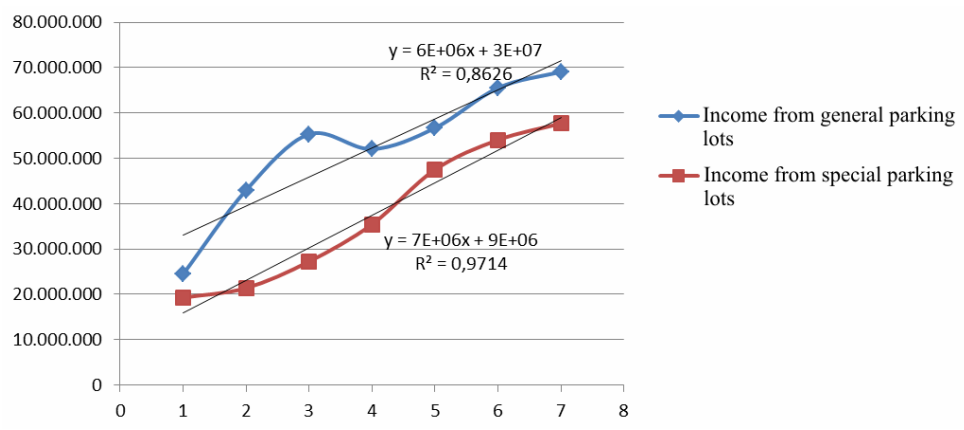

Figure 7

Upward trend of income from open and special car parks

Income from open car parks has increased due to three reasons:

- Users are able to pay for the parking in a less complicated way, through SMS system, which shortens the payment time.

- Payment control, performed by the employees of the Parking Service Company, is more effective; the psychological effect of the necessity of payment is enhanced.

- The number of available parking spaces has been increased, as a result of the introduction of the information system.

The payment of parking at special car parks is also better, because before the introduction of the information system it was practically impossible to control parking attendants at special car parks. As a result of its introduction, payment control, primarily the control of parking attendants by the management, has become more effective. A more detailed structure of sold tickets is shown in Table 2 and Figure 8.

Based on everything herin, we can see that there is a positive trend, i.e. that the introduction of the information subsystem for parking management has led to a better use of the existing parking areas at special car parks . It must also be noted that in this period (2007-2013) two special car parks were closed, which reduced the number of effective parking spaces which is another indicator of the positive effects of the IS introduction.

Table 2

The structure of sold tickets

\begin{tabular}{|l|l|l|l|l|l|l|l|}
\hline Year & 2007 & 2008 & 2009 & 2010 & 2011 & 2012 & 2013 \\
\hline 1-hour parking tickets & 720 & 961 & 1.274 & 1.353 & 1.456 & 1.181 & 1.133 \\
\hline Scratch parking tickets & 130 & 193 & 151 & 96. & 87 & 47 & 79 \\
\hline Residential tickets & 3.48 & 3.52 & 3.45 & 3.34 & 3.54 & 3.57 & 3.60 \\
\hline
\end{tabular}


The structure of sold tickets indicates both some positive and some negative trends. The sale of classic one-hour SMS tickets has increased, which is in line with previously given facts; however, there is also a negative trend related to multi-hour tickets sale. The reason for that are some additional parking limitations in payment zones (which is not directly connected to the information system), as well as the reduction of purchase of classic paper multi-hour scratch tickets and more frequent use of SMS charging system which is a part of the information system - therefore, it is a positive effect, basically, regardless of the negative trend, because it directs users to the application of more efficient payment system.

As for the residential tickets, the status is slightly positive, but it is not the consequence of IS itself, but of some other factors which, are not the subject of this work.

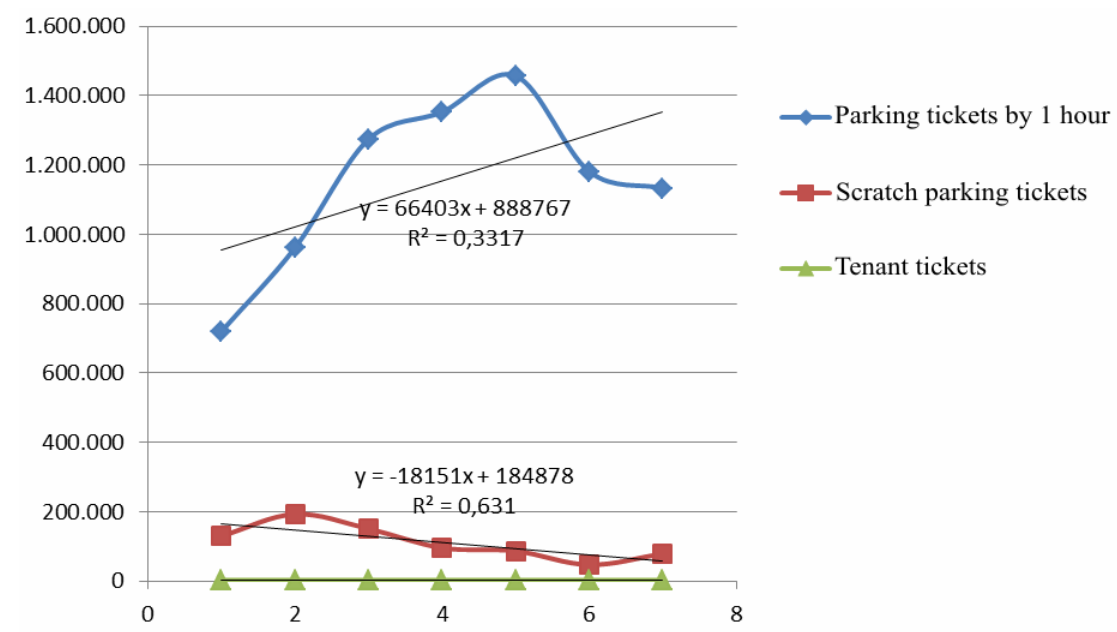

Figure 8

The structure of sold tickets

\section{Conclusion}

The analysis presented in this paper is a basic and important step in the development of the information system for car parks management. The advantages of applying the information system (IS) in the parking service company management are obvious, because they help the creation of a rational framework for justifying the existence of a parking service company. Setting up of an information system in this type of company can be considered on three levels, with each level allowing for the improvement of procurement and analysis of information: level of service, level of process management and level of integration in the communal system. 
The main purpose of this paper is to provide an overview of the key segments in the development of the information system for a parking service company analysis and determining of information flow. In that way a precise definition of information flow is obtained and expressed in decomposition diagrams. The presented analysis has enabled the formation of the relational database model, which is also given in the paper. The results presented here are a fundamental and crucial element in the development of the information system of a parking service company. Based on detailed analysis, it is possible to form the physical level of database and software solutions, which will allow access to all the information from the observed business activity. The presented segment of the information system is an integral part of the overall information system of a parking service company.

In this paper, the results have been presented in a methodological fashion, enabling a detailed understanding of these issues and, in general, the creation of the basis for the development of an information system for a parking service company.

\section{Acknowledgement}

The research presented in this paper was supported by the Ministry of Education and Science of the Republic of Serbia, Grant III-44010, Title: Intelligent Systems for Software Product Development and Business Support based on Models.

\section{References}

[1] The public company „Parking Service“ Kragujevac, Available at: www.parkingservis.rs/ (Accessed: 30.09.2013)

[2] Assembly of the City of Kragujevac, Available: www.kragujevac.rs/Skupstina_grada-40-1 (Accessed: 30.09.2013)

[3] Law on Traffic Safety on Roads, Available at: www.parkingservis.rs/images/pdf/zakon_o_bezbednosti_saobracaja_na_put evima.pdf (Accessed: 30.09.2013)

[4] Parking Lot Service System, Oki Electric Industry Co., Ltd. Available at: www.oki.com/ (Accessed: 30.09.2013)

[5] Caicedo, F. - Blazquez, C. - Miranda P.: Prediction of parking space availability in real time, Expert Systems with Applications, Vol. 39, No. 8, 2012, pp. 7281-7290

[6] Chrest, A. P.: Parking Structures: Planning, Design, Construction, Maintenance, and Repair, Kluwer Academic Publishers, Massachusetts, 2001

[7] Stair, R. - Reynolds, G.: Principles of Information Systems, Cengage Learning, Boston, 2013 
[8] Olson, D. L. - Kesharwani, S.: Enterprise Information Systems: Contemporary Trends and Issues, World Scientific, Singapore, 2010

[9] Curtis, G. - Cobham, D.: Business Information Systems: Analysis, Design and Practice, Pearson Education, Harlow, England, 2008

[10] Maria van der Heijden, J. G.: Designing Management Information Systems, Oxford University Press, Oxford, 2009

[11] Johannesson, P. - Söderström, E.: Information Systems Engineering: From Data Analysis to Process Networks, Idea Group Inc (IGI), Hershey, 2008

[12] Narang, R.: Database Management Systems, PHI Learning Pvt. Ltd., New Delhi, 2011

[13] Silberschatz, A. - Korth, H. F. - Sudarshan, S.: Database System Concepts, McGraw-Hill, New York, 2011

[14] Coronel, C. - Morris, S.: Database Systems: Design, Implementation, and Management, Cengage Learning, Stamford, USA, 2014

[15] Ritchie, C.: Database Principles and Design, Cengage Learning IMEA., London, 2008

[16] Garcia-Molina, H. - Ullman, J. D. - Widom, J.: Database systems: the complete book, Pearson Education, UK, 2011

[17] Elmasri, R.: Fundamentals of Database Systems, Pearson Education, UK, 2008

[18] Sandor, Z. P. - Csiszar, C.: Development Stages of Intelligent Parking Information Systems for Trucks, Acta Polytechnica Hungarica , Vol. 10, No. 4, 2013, pp. 161-174

[19] Sabherwal, R. - Becerra-Fernandez, I.: Business intelligence, Wiley, Hoboken, NJ, 2011

[20] Loshin, D.: Business Intelligence: The Savvy Manager's Guide, Morgan Kaufmann, Waltham, USA, 2012

[21] Vitt, E. - Luckevich, M. - Misner, S.: Business Intelligence, Microsoft Press, Redmond, USA, 2010 